\title{
PASADO Y PRESENTE DEL PATRIMONIO: INVENTARIOS \\ POSTDESASTRE. LA ERMITA DE SAN ANTONIO Y \\ EL INCENDIO DE GARAFÍA DE 1902 (LA PALMA)
}

\author{
Antonio Marrero Alberto* \\ Universidad Adolfo Ibánez (Santiago de Chile)
}

\section{RESUMEN}

En este artículo pretendemos abordar la importancia de los documentos e inventarios de bienes elaborados tras desastres naturales o antrópicos. Para ejemplificarlo, estudiaremos el caso del incendio de la ermita de San Antonio de Padua en el monte de Garafía en 1902 y la descripción detallada que se hace de todo lo que contenía el edificio antes de que fuera consumido por las llamas. Nos planteamos así el objetivo de revivir un santuario de fundación temprana para la historia de las Islas Canarias y que sigue siendo lugar de peregrinación para los habitantes de la isla de La Palma.

Palabras clave: capilla, San Antonio, inventario, incendio, La Palma, Islas Canarias.

PAST AND PRESENT OF THE HERITAGE: POST-DISASTER INVENTORIES. THE SAN ANTONIO'S CHAPEL AND THE GARAFIA'S FIRE OF 1902 (LA PALMA)

\section{Abstract}

In this article we intend to address the importance of documents and inventories of goods made after natural or anthropogenic disasters. To exemplify it, we will study the case of the fire of the hermitage of San Antonio de Padua in the mountain of Garafía in 1902 and the detailed description that is made of everything that contained the building before it was consumed by the flames. We set ourselves the objective of reviving an early foundation sanctuary for the history of the Canary Islands and which continues to be a place of pilgrimage for the inhabitants of the island of La Palma.

Keywords: chapel, San Antonio, inventory, fire, La Palma, Islas Canarias. 


\section{INTRODUCCIÓN}

Los inventarios de bienes en edificios religiosos son fundamentales para los historiadores del arte. La caída en desuso de las imágenes, los cambios de estilo y los procesos bélicos o que conlleven la destrucción del patrimonio (por ejemplo, las desamortizaciones) cambian la fisonomía interior de dichos inmuebles, quedando como único y fiel testigo de su pasado artístico las fuentes de archivo. Pero ¿qué nos queda para la investigación cuando, fruto de un incendio o desastre natural, desaparecen también los documentos de registro del edificio? Poniéndonos en el peor de los casos, tenemos el caso de la ermita de San Antonio de Padua, en el monte de Garafía (La Palma), consumida por las llamas en 1902 y de la cual contamos con un inventario, inédito, posterior al desastre, que enumera con todo lujo de detalles los bienes que poseía el templo. Aunque resulte complicado seguirle la pista a este tipo de documentos, pues, como en el caso que nos ocupa, se encontraba en el archivo de otra parroquia, su hallazgo arroja luz en el estudio de este tipo de edificaciones, supervivientes a las adversidades ${ }^{1}$.

\section{ERMITA DE SAN ANTONIO DE PADUA (GARAFÍA). LOCALIZACIÓN Y DESARROLLO ARQUITECTÓNICO}

Ubicada en el municipio de Garafía, en el norte de la isla de La Palma (Islas Canarias), en medio de una zona boscosa, encontramos la ermita de San Antonio de Padua, popularmente conocida como San Antonio del Monte. Es, junto con el templo parroquial de Nuestra Señora de la Luz, el más importante centro y punto de referencia religioso de todo el municipio.

Se trata de un edificio que responde a la tipología de arquitectura popular, con paredes enlucidas en blanco y sin decoración atribuible a un estilo concreto, quedando ésta relegada a los sillares de perfil irregular que se colocan en las esquinas de los volúmenes que componen el edifico, dando solidez y asiento. La fachada principal cuenta con un arco de medio punto realizado en piedra basáltica y un balcón de madera, de raigambre mudéjar (solución muy extendida en el archipiélago), con una puerta del mismo material y cristal que lo comunica con el coro superior, ofreciendo iluminación natural a la nave. La cornisa superior pasa a la espadaña con un perfil cóncavo y ésta, con dos vanos para sendas campanas, se perfila con perfil convexo, rematándose a su vez con una cruz. El lado colateral de la epístola presenta puerta y ventana sobre ésta, que funciona como entrada opcional. En el mismo lado, encontramos una originalidad en las islas que es la situación del vela-

* CONICYT postdoctorado FONDECYT 2018 n. 3180174 en Arte, Universidad Adolfo Ibáñez (Santiago de Chile). Email: antonio.marrero@uai.cl.

${ }^{1}$ El documento que es objeto de nuestro estudio fue hallado en el archivo parroquial de Tijarafe. A dicha iglesia y al Ayuntamiento agradecemos la oportunidad de realizar una estancia de investigación que, entre oros resultados, permitió el desarrollo de esta investigación. 


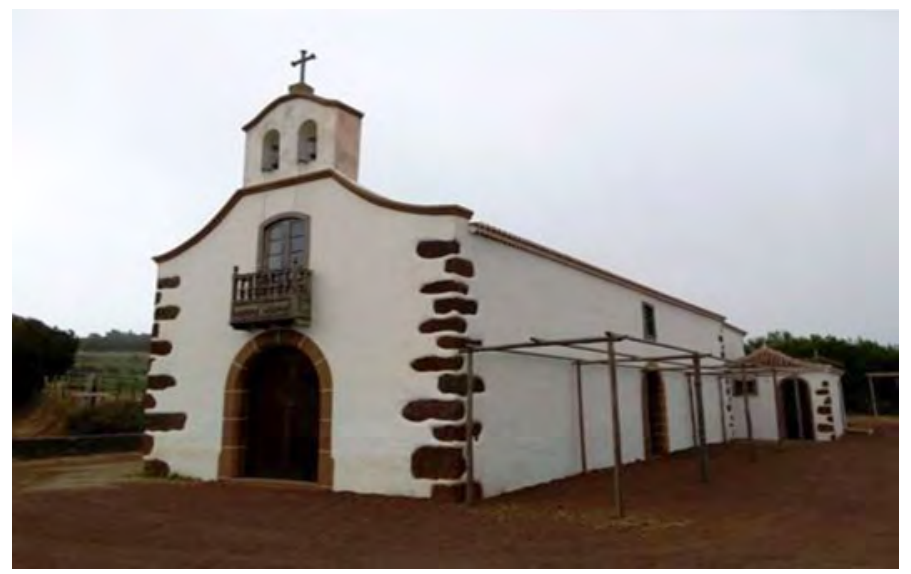

Foto 1. Anónimo. Exterior (inicios del siglo xvi, reconstrucción de la primera década del siglo xx). Ermita de San Antonio de Padua. Garafía, España (foto del autor).

rio en un espacio independiente, con entrada y ventana propia, lo cual también ocurre con la sacristía, aunque ambos formen parte del mismo volumen. Finalmente, la otra zona destacada es el presbiterio, que es de menores dimensiones que la nave y presenta contrafuerte en el lado del evangelio. Los espacios mencionados se cubren al interior con artesonados de madera que atestiguan la pervivencia cultural mudéjar en las islas, mientras que al exterior aparece la clásica teja árabe, democratizada a todos los edificios canarios.

Aunque el exterior no haya cambiado en demasía con respecto a la estructura original, el interior presenta suelo de cerámica con líneas de mármol y todos los elementos lígneos tuvieron que ser rehechos tras el incendio acaecido en 1902. La capilla mayor se diferencia del resto mediante un arco toral en piedra volcánica rojiza y escalón de acceso. A su vez, ésta comunica con la sacristía, y es en este acceso entre ambas donde, a modo de testigo, se acristaló la piedra ennegrecida por el fuego a modo de recuerdo para el futuro.

La ubicación resulta enigmática, ya que la ermita se encuentra alejada del centro poblacional, máxime teniendo en cuenta que se trata de un territorio abrupto y escarpado. La razón por la que se eligió este lugar es por la extraordinaria calidad de su suelo para la economía agrícola, la cual hizo del pueblo de Garafía un lugar próspero y rico. Sobre ello conviene citar las palabras de autor Leoncio Afonso cuando dice:

Esta zona es donde más extensión ocupan los terrenos de «quintos». Se trata de un suelo rico en humus, bastante profundo por la fácil alteración de los lapillis y enriquecido por el manto de laurisilva que los cubrió. Las formas relativamente suaves del terreno facilitan las labores agrícolas, y las abundantes lluvias, además 


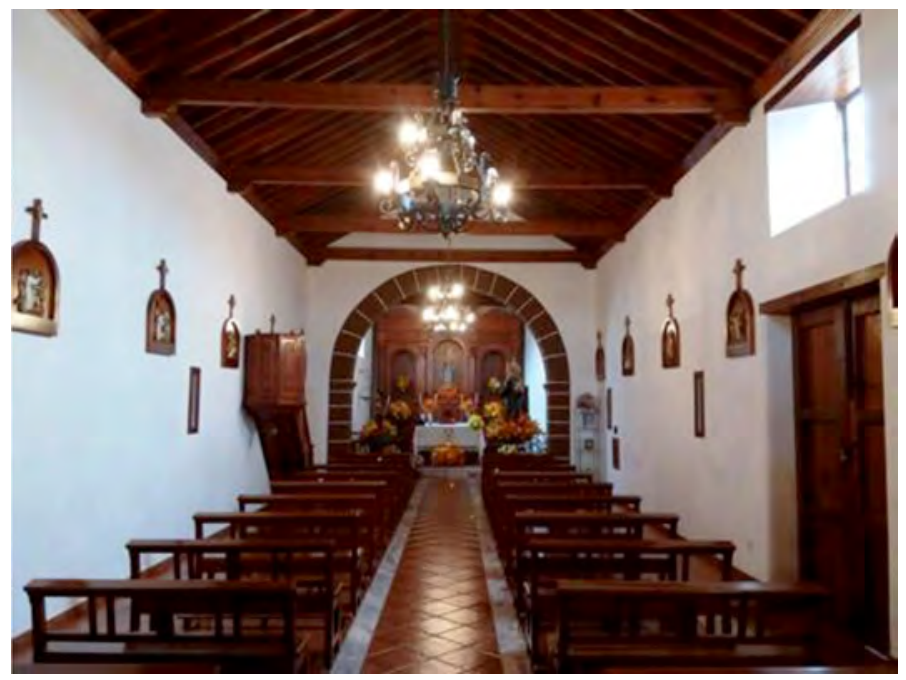

Fig. 2. Anónimo. Interior (inicios del siglo xvi, reconstrucción de la primera década del siglo xx). Ermita de San Antonio de Padua. Garafía, España (foto del autor).

de la nubosidad, son la garantía de las cosechas. Esta zona era cerealista, pero se ha convertido en la del tagasaste y los pastizales.

Para a continuación tocar, de manera muy tangencial, la existencia de los dos núcleos devocionales anteriormente mentados:

Es difícil saber cómo evolucionó la población de esta zona en los primeros siglos, debido al pleito entre la parroquia de San Antonio, cerca de Llano Negro, y la de la Luz en la zona baja; hubo un momento en el siglo xvi en que existieron ambas, pero más tarde la de la Luz quedó como única; suponemos que ambas inflaron sus datos para obtener la hegemonía ${ }^{2}$.

La riqueza de la ermita, cuestión maniquea con respecto a su localización, se nos hará evidente cuando abordemos el inventario de piezas existentes antes del mencionado desastre.

2 Afonso Pérez, Leoncio (2004): Miscelánea de temas canarios. Islas Canarias: Centro de la Cultura Popular Canaria, Gobierno de Canarias, pp. 129-130. 


\section{FUNDACIÓN DE LA ERMITA Y LITIGIOS CON LA IGLESIA DE NUESTRA SEÑORA DE LA LUZ}

Para los investigadores Orribo Rodríguez y Rodríguez Martín no cabe ninguna duda de que el primer templo católico levantado en la localidad de Garafía fue el de San Antonio de Padua, a cargo de colonizadores portugueses allá por los inicios del siglo $\mathrm{XVI}^{3}$. La iglesia de la Virgen de La Luz comenzó su construcción décadas después y se bendijo el 6 de febrero de 1552, todavía en proceso de construcción ${ }^{4}$. Citando a los autores anteriores, «ambas iglesias estuvieron sin sacerdote hasta 1557, fecha en que por Real Cédula del 8 de octubre es nombrado uno para la iglesia de San Antonio». Esto llevó a que los vecinos de la zona de abajo terminaran aceleradamente su iglesia y reclamaran al obispo que el cura estuviera en su iglesia y no en el monte, donde no había prácticamente vecino y el frío dificultaba el desarrollo eucarístico de manera adecuada. Con autorización episcopal, llevaron al santo paduense a la actual parroquia, dejando la ermita que es objeto de nuestro estudio bajo la advocación del apóstol Santiago. Realmente, se trataría de una estratagema política más que religiosa, pues de este modo se intentaba desbaratar el núcleo portugués establecido en torno al templo de la montańa, imponiendo la titularidad del patrón español en la misma. Sus vecinos lograron, tras la consabida protesta, que el santo regresara a su lugar original, pero el sacerdote permaneció en la zona de abajo, celebrando misa en San Antonio cada quince días.

Regulo Pérez, en su libro sobre el municipio de Garafía, y su desarrollo histórico, incide en todos los aspectos mentados. Resulta destacable lo vertido por éste, sobre todo por lo que tiene de original y personal, cuando dice que, en su opinión, aunque sin documentos en que apoyarse y que expone públicamente por primera vez,

... los moradores ricos portugueses, que ocuparon casi una legua cuadrada de Garafía, eran judíos de los expulsados por el rey don Manuel de Portugal a partir de 1496, pues de otra manera no se explica que portugueses ricos vinieran a poblar el

${ }_{3}^{3}$ Orribo Rodríguez, Tomás y Rodríguez Martín, Néstor (1997): Del lugar de Tagalguen. Historia, tradiciones, gentes y recuerdos de la Garafía de ayer. La Laguna: Ayuntamiento de la Villa de Garafía, pp. 24-25.

${ }^{4}$ En el año 1588 ya contaba con las dos naves, dos capillas y pila bautismal, la cual había estado primeramente en la ermita de San Antonio de Padua. En la misma documentación que nos refiere lo antedicho, se lee: «No hay más que una hermita en la jurisdicción, dedicada a San Antonio de Padua en el Monte [...] que se arruinó en 8 de Agosto de 1848. [...] La hermita de San Antonio en el Monte se ha reedificado en 1854, á consta de los vecinos, y se colocó la imagen del Santo el 12 de Junio, víspera de él». Desconocemos el motivo que arruinó el templo, pero no se trata del incendio del que hablaremos posteriormente, pues éste acaeció en 1902 y el texto que nos ocupa es de 1855 . Sí que tenemos constancia del estado lamentable en el que se encontraba, lo cual puede estar vinculado a un posible derrumbamiento (parcial o total) y posterior intervención. Real Sociedad La Cosmológica, Santa Cruz de La Palma (RSCP). Tomo I de Curiosidades. Indice de los libros parroquiales del pueblo de Tijarafe, y otras varias noticias referentes a las antigüedades de esta isla. Noticias de la fundación de las Parroquias de esta Isla de la Palma, tomadas de las relaciones dadas por los mismos Párrocos al Gobierno eclesiásticos de la Diócesis en 1851, 269-270. 


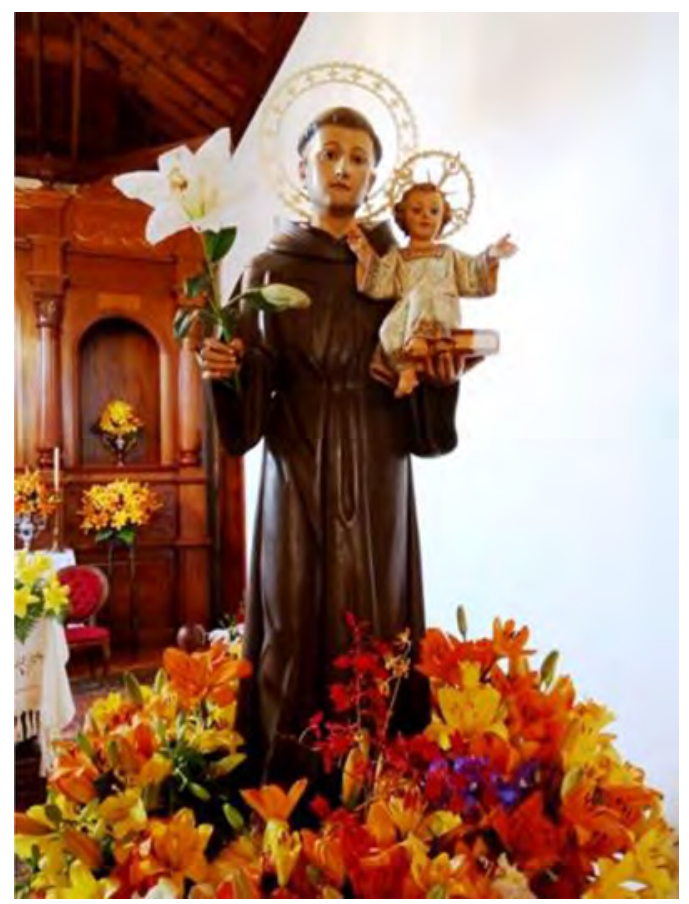

Foto 3. Anónimo. San Antonio de Padua (siglo xx). Escayola policromada. Ermita de San Antonio de Padua. Garafía, España (foto del autor).

sitio más fragoso e inaccesible de La Palma, a oscurecerse allí y a dejar vestigios sólo en la antroponimia, en la toponimia, en el habla y en los libros sacramentales de la parroquia de la Luz, los cuales durante la segunda mitad del siglo xvi y comienzos del Xvil se redactaron en portugués por cuatro curas sucesivos; sólo, repito, el huir de la persecución, de la Inquisición, y muchos acaso de ser quemados vivos -como lo fueron aquí en Canarias, otros portugueses de religión hebrea-, puede dar cuenta de un poblamiento tan singular, ya que lo normal es que los lugares más alejados, abruptos y expuestos los pueblen los más necesitados y pobres. A Garafía la llamó el obispo Cámara y Murga (1631), "la más quebrada áspera tierra del mundo».

En cuanto al traslado del santo en cuestión, afirma que se produjo a principio de 1552, aunque los moradores de las montañas no se conformaron y cuando el visitador episcopal, D. Luis de Padilla, estuvo en La Palma (entre 1552 y 1557), por súplica de éstos, envió un clérigo a Garafía con el mandato de que volviera dicha imagen y sus ornamentos a su templo primigenio. Ante esto, D. Diego Yanes pidió

5 Régulo Pérez, Juan (1990). Garafía y su ilustre historia. Madrid: Ed. La Palma, pp. 31-33. 
al visitador que la parroquia, sin titular por el traslado del san Antonio, se pusiera bajo la advocación de la Virgen de la Luz, petición a la que accedió el visitador. Esto debió de suceder antes de 1557, naciendo la parroquia de Nuestra Señora de la Luz. Para evitar más injerencias competenciales, en el verano de 1558 se crearon los curatos de San Antonio y de la Luz, sirviendo el párroco en las dos iglesias, siendo los libros sacramentales llevados por el curato de la Luz, los cuales se iniciaron en 1560.

Es vox populi la duda en torno a la fundación de ambos edificios religiosos, pues, aunque existen las publicaciones citadas anteriormente, ninguno ha referenciado ni transcrito documentación primera que permita cerrar el capítulo en torno a cuál es la más antigua. Finalmente, la visita del licenciado D. Juan Pinto de Guisla el 15 de junio de 1679 nos da la respuesta: «Visitose la ermita de San Antonio de Padua, de este distrito; es muy antigua y fue parroquia antes que la de la Luz». A su vez, al margen presenta una anotación anacrónica con la anterior, ya entrado el siglo xx, que dice así: «Esta ermita y la casa de los romeros, que era contigua, desapareció el 12 de agosto de 1902, víctima de un voraz incendio que destruyó los montes todos de Garafía así como también algunas casas, pajares, bodegas» ${ }^{6}$.

\section{EL INCENDIO DE 1902: LA DESTRUCCIÓN DEL EDIFICIO}

Tras lo expuesto, se hace evidente la importancia de la ermita, su trascendencia histórica y su vinculación a una zona que es, tradicionalmente, rica en exportación de materias primas. El incendio debió de ser algo monstruoso, pues en un panfleto editado por la Cruz Roja con motivo de la recaudación de dinero para ayudar a los afectados por el desastre se lee:

A las 11 horas del referido día 12 de Agosto vióse incendiado el lugar donde dicen «La Fuente del Sauzo», en los montes del Tablado, propagándose con asombrosa rapidez, avivado por un viento impetuoso; convirtiendo en cenizas cuantos árboles encontraba a su paso por muy gigantescos que fuesen; igual suerte les tocó a los dilatados plantíos de tagasastes; las cosechas que aun se encontraban en las eras; las casas, pajares, bodegas graneros y lagares en toda la extensión que comprenden los siguientes sitios, recorridos por el devastador elemento: Barranco de Carmona, Zoras, Capitán, Las Zarzas, San Antonio, Riachuelo, Llano del Negro, Cabezadas de Santo Domingo, Bailadero, Zabres, Hoya Grande, Cueva de Agua, Barranco de Briesta, Castillo y Lomada Grande, en el pago de las Tricias; y los montes de Don Pedro, Tablado y Franceses (...). En los demás, el terrible elemento fue horroroso, sin precedente alguno en esta Isla. Montes tan precioso como los llamados de «La Barrera», «Dividido», «Cuevas Coloradas», «Guanches», etc., han desaparecido completamente. El encantador Valle del Negro, las pintorescas campiñas de Haya Grande, lo mismo que el bonito e histórico Valle de San Antonio, se

${ }^{6}$ Archivo Parroquial de Nuestra Señora de la Luz, Garafía (APNSLG, Garafía). Libro de Visitas, 15-VII-1679. Transcrito por: Lorenzo Rodríguez, Juan B. (2010): Noticias para la historia de La Palma. La Palma: Cabildo Insular de La Palma, Gobierno de Canarias, 150-151. 


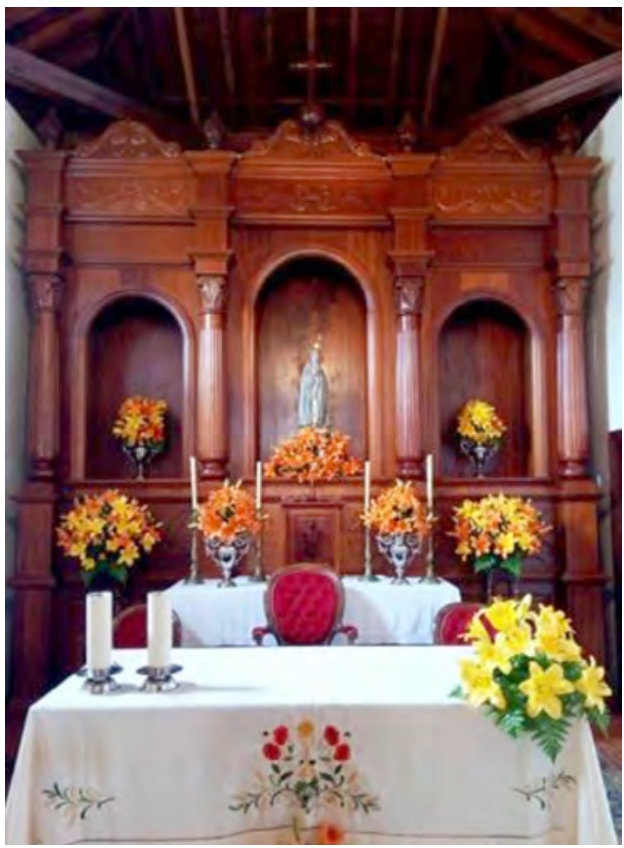

Foto 4. Anónimo. Retablo mayor (siglo xx). Madera.

Ermita de San Antonio de Padua. Garafía, España (foto del autor).

sobrecoje el ánimo al contemplarlos. Muchísimos animales vacunos, lanar, cabrío y de cerda, y un sinnúmero de aves de corral se encontraban carbonizados en los sitios recorridos por el incendio. Los daños no pueden aun precisarse. El número de casas, pajares albergues, chozas, bodegas y lagares destruídos por el fuego pasan de 800; y no se diga que eran solo miserables casuchas, pues, un regulas número, estaban cubiertas con tejas, siendo muchas de dos pisos?

No hubo periódico o diario en las Islas Canarias que no se hiciera eco de la noticia, por lo virulento y espeluznante que de lo sucedido se contaba en todos los rincones del Archipiélago ${ }^{8}$.

7 Lorenzo, Juan (1902): «San Antonio del Monte», en Boletín Mensual de la Cruz Roja, 5, pp. 75-78.

${ }^{8}$ Entre otros: El Grito del pueblo: semanario político y de intereses generales. Santa Cruz de La Palma, 16/VIII/1902, p. 1; La Opinión: periódico liberal-conservador. Santa Cruz de Tenerife, 19/VIII/1902, p. 2; La Región Canaria. La Laguna, 4/IX/1902, p. 3; Las Canarias: órgano hispano-canario. Madrid, 5/IX/1902, p. 3. 


\section{PASADO Y PRESENTE DEL PATRIMONIO DE LA ERMITA: EL INVENTARIO POSTDESASTRE DE 1902 Y LA IMPORTANCIA DE LAS FUENTES DOCUMENTALES}

Debido a la relevancia de la ermita de San Antonio de Padua, ampliamente referida y argumentada, lo implacable del fuego y su desaparición en muy poco tiempo, y la sensibilidad del párroco estante en ese momento, D. Antonio Sánchez Rodríguez, se decide realizar un inventario pormenorizado de todo el patrimonio del edificio antes de su destrucción 9 . Subdividido por tipos de bienes, resulta llamativa la existencia de un único retablo, de un solo cuerpo, tres calles y ático. En el nicho central se ubicaría la imagen del santo patrón ${ }^{10}$ y a los lados, san Roque y san Bernardo. En el nicho del mencionado ático, se encontraba ubicada una representación del Ángel de la Guarda.

Las tres imágenes del único cuerpo del retablo (san Antonio, san Bernardo y san Roque) contaban con ornamentos propios, ya sean capas y telas a modo de vestimenta, así como diademas de plata los dos primeros, una diadema de latón sobredorado para el tercero, potencias de plata para el niño Jesús que portaba el santo titular, así como una vara de azucena de plata, atributo de éste. Además, dentro del conjunto de orfebrería, la ermita contaba con cáliz, patena, campanilla, vinajeras y solio de plata sobredorada, hoja de tabaco de plata (el cultivo de esta planta y la elaboración del puro palmero de sobra conocidos internacionalmente) y basa metálica para san Antonio.

Son numerosos los elementos de madera y piedra que enriquecen el ajuar de la ermita, así como herramientas para el cuidado de la misma y la celebración del rito eucarístico. Destacamos el ara o piedra de altar, el púlpito con crucifijo y la existencia de un órgano, que estaría situado en el coro alto que se encuentra sobre la puerta principal y comunica con el balcón que se describía al principio.

De toda aquella opulencia sólo quedaron restos inidentificables y una campana que por su situación en la espadaña se salvó de las llamas. Tal vez sea ésta la que D. José Tovar insistía en que

... se debía encargar en el Norte [...], habida cuenta que de las tres que poseía una estaba inútil y otra era de reducido tamańo, ya que pertenecía a la ermita de San Antonio, a donde ordenó Tovar se devolviera en cuanto llegase la nueva. [...] El

9 Ver Ap. Documental n. ${ }^{\circ}$ 1. También tenemos el caso de planos o diagramas realizados posteriores al desastre, como es el caso las techumbres mudéjares de la iglesia de la Concepción en Los Realejos (Tenerife, Islas Canarias), que ardieron en 1978: Marrero Alberto, Antonio (2018). "Artesonados: planos póstumos y reconstrucción. La Iglesia de la Concepción (Los Realejos)» en Revista Estoa, 13 (2018), pp. 123-132.

${ }^{10}$ Lorenzo Rodríguez, Juan B. (2010): Noticias para la historia de La Palma. La Palma: Cabildo Insular de La Palma, Gobierno de Canarias, p. 150. La policromía del nicho corrió a cargo del beneficiado de Garafía, D. Luis Rodríguez, el cual legó una cantidad de dinero para que se pintase. 


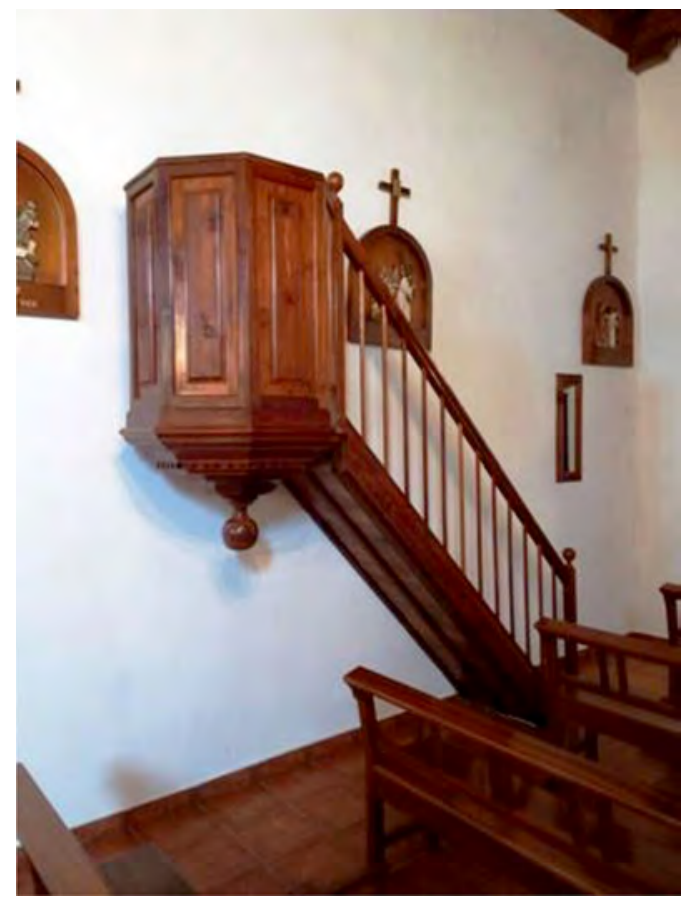

Foto 5. Anónimo. Púlpito (siglo xx). Madera. Ermita de San Antonio de Padua. Garafía, España (foto del autor).

mismo día visitó la ya citada ermita de San Antonio, sobre la que únicamente destacó su carácter de fábrica nueva ${ }^{11}$.

La espadaña cuenta con dos campanas, y su situación a gran altura (en la espadaña) y lo dificultoso de acceder a ellas sólo permite elucubrar si será una de ésas la que menciona la Dra. Ana Quesada en el referido artículo y si será también la que se salvó del pavoroso incendio.

En la actualidad, la edificación que observamos es una intervención en profundidad para la recuperación de la primitiva ermita (desconocemos el estado en el que se encontraba tras el desastre y qué partes son originales y cuáles no), mientras que todo el patrimonio que alberga es del siglo xx: la madera (techumbres y coro) es de reciente hechura, la pila bautismal en piedra volcánica roja compuesta por taza y

11 Quesada Acosta, Ana María (1993): «La visita de Don José Tovar a la Palma: (171718). Aspectos artísticos» en I Encuentro Geografía, Historia y Arte (Tomo de Arte). La Palma: Exmo. Cabildo Insular de la Isla de La Palma, p. 147. 


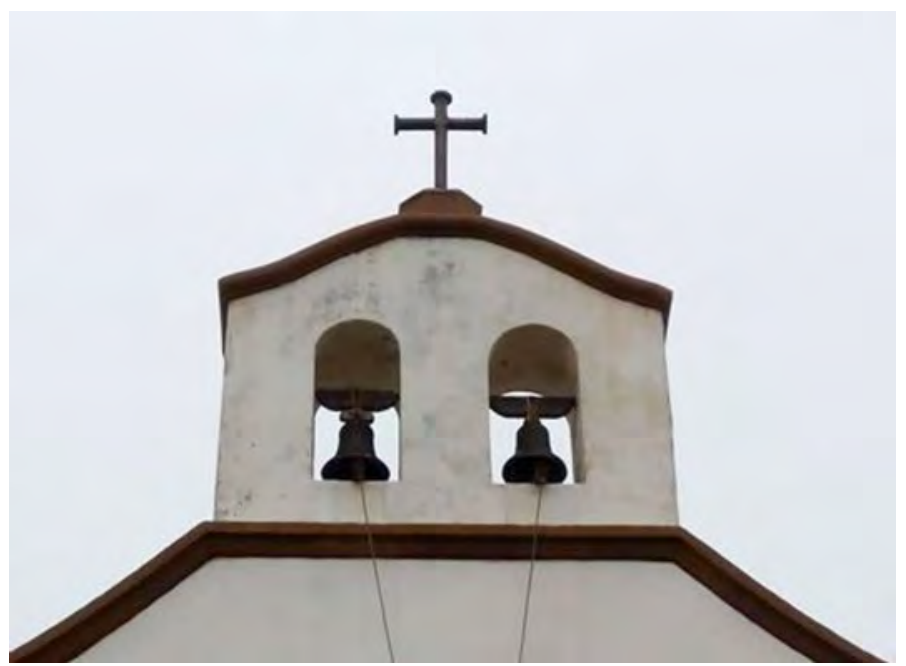

Foto 6. Anónimo. Espadaña con dos campanas (inicios del siglo XVI, reconstrucción de la primera década del siglo $\mathrm{xx}$ ).

Ermita de San Antonio de Padua. Garafía, España (foto del autor).

soporte, el vía crucis, el púlpito y el retablo en madera vista, las lámparas y utensilios para el culto en plata y otros metales, y las imágenes que hoy se veneran. Entre éstas destacan san Antonio de Padua con el Niño Jesús en brazos, san Isidro Labrador $^{12}$ y Nuestra Señora de Fátima, ésta última de reducidas dimensiones. El retablo, de un único cuerpo y tres calles con sendos nichos, prescinde del ático y se remata con una cruz. Tres sillas y el altar de madera completan el conjunto, de una marcada sobriedad que no permite imaginarnos el aspecto primigenio. En la sacristía, además del consabido mobiliario para la salvaguarda de los ornamentos litúrgicos y otros enseres, encontramos una virgen entronizada dentro de un tabernáculo acristalado y un corazón de Jesús, ambas piezas coetáneas al resto.

\section{CONCLUSIÓN}

Del artículo se deriva la necesidad de atender a las fuentes documentales y establecer elucubraciones histórico-artísticas a partir de inventarios que, tal vez, no son reflejo fiel de los bienes que se conservan en la actualidad, pero que permiten

12 Reza en una plaza situada en el lado frontal de la basa lo siguiente: «REgALO DE Eutimio Martín Pérez hijo de Garafía, a la ermita de san Antonio. enero 1962». 


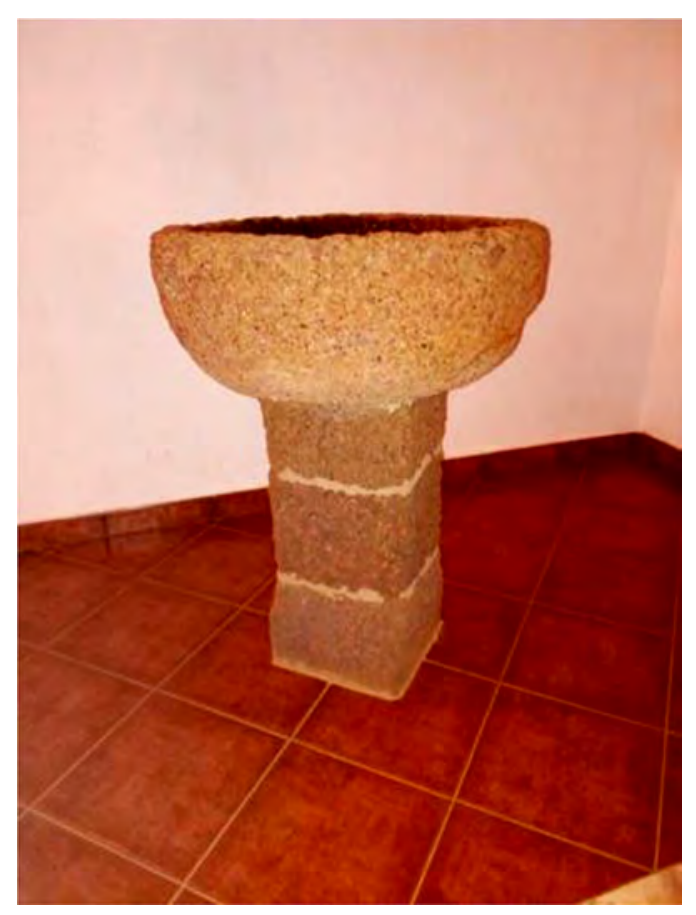

Foto 7. Anónimo. Pila bautismal (siglo xx). Piedra volcánica roja. Ermita de San Antonio de Padua. Garafía, España (foto del autor).

postular teorías en cuanto a contribuciones, dataciones e importancia de las fundaciones. Al mismo tiempo, la posibilidad de encontrar documentos fuera de sitio (ya sea en archivos parroquiales cercanos, así como en instituciones que los aglutinan y catalogan) obliga al investigador a ampliar su campo de acción.

Aunque el aspecto actual no nos dé una idea de su apariencia antes del incendio de 1902, es fundamental la existencia del inventario comentado para el conocimiento de un patrimonio desaparecido. Éste no hace sino dar fundamento, con su riqueza, de que nos encontramos con una ermita que tuvo un papel protagonista en la localidad, siendo incluso hoy en día lugar de peregrinaje de todos los palmeros que se acercan una vez al año con motivo de su festividad. Es de recibo ofrecer un agradecimiento póstumo al párroco, D. Antonio Sánchez, pues de su sensibilidad y preocupación por reflejar lo que fue, podemos definir y concretar la realidad de la Ermita de San Antonio de Padua, en el monte de Garafía. 


\section{BIBLIOGRAFÍA}

Afonso Pérez, Leoncio (2004): Miscelánea de temas canarios. Islas Canarias: Centro de la Cultura Popular Canaria, Gobierno de Canarias.

Lorenzo, Juan (1902): «San Antonio del Monte», en Boletín Mensual de la Cruz Roja, 5, pp. 75-78.

Lorenzo Rodríguez, Juan B. (2010): Noticias para la historia de La Palma. La Palma: Cabildo Insular de La Palma, Gobierno de Canarias.

Marrero Alberto, Antonio (2018). «Artesonados: planos póstumos y reconstrucción. La Iglesia de la Concepción (Los Realejos)», en Revista Estoa, 13 (2018), pp. 123-132.

Orribo Rodríguez, Tomás y Rodríguez Martín, Néstor (1997): Del lugar de Tagalguen. Historia, tradiciones, gentes y recuerdos de la Garafía de ayer. La Laguna: Ayuntamiento de la Villa de Garafía.

Quesada Acosta, Ana María (1993): «La visita de Don José Tovar a la Palma: (1717-18). Aspectos artísticos» en I Encuentro Geografía, Historia y Arte (Tomo de Arte). La Palma: Excmo. Cabildo Insular de la Isla de La Palma.

RÉgulo Pérez, Juan (1990): Garafía y su ilustre historia. Madrid: Ed. La Palma. 


\section{APÉNDICE DOCUMENTAL N. ${ }^{\circ} 1$}

El párroco que suscribe ante el Notario Eclesiástico y testigos que al final firmarán, manifiesta que el doce de agosto de mil novecientos dos, se quemó la Ermita de San Antonio de Padua a causa de un voraz incendio ocurrido en los montes de este término municipal, siendo por lo tanto quemados

\section{IMÁGENES}

Primeramente: una imagen de talla de San Antonio de Padua con el niño Jesús en las manos colocado en su nicho pintado de varios colores.

Iten: una imagen de talla de San Bernardo, colocado en su nicho.

Iten: una Imagen de San Roque, colocado también en su nicho, como las anteriores en el retablo del altar mayor, [único] que existía en la expresada Ermita y que remataba un nicho conteniendo el Angel de la Guarda.

\section{Cosas de Plata y otros metales}

Primeramente: un caliz con patena y cucharilla de plata.

Iten: un solio grande de plata sobredorado con una [parte] verde en el centro del cual se encontró un pedacito [deja]do por el fuego y que existe en el Archivo parroquial.

Iten: dos diademas de plata, un de San Antonio para el [dicxo] y otra de San Bernardo.

Iten: una diadema de latón sobre dorado de San roque.

Iten: tres potencitas de plata sobre doradas del niño.

Iten: una cetre de cobre.

Iten: una campanilla pequeña de mano para el altar.

Iten: una azucena de plata de San Antonio.

Iten: un par de vinageras en su platillo de expeltre.

Iten: Una basa del santo.

\section{Cosas de MADERA y PIEDRA}

Primeramente: la piedra de ara del altar, recogiéndose algunos datos que se estudian en el Archivo Parroquial.

Iten: una cruz para la manga.

Iten: otra muy antigua para ídem (no existía).

Item: una cruz con crucifijo para el altar.

Iten: un atril para el Altar.

Iten: otro para el coro.

Iten: dos cajas grandes viejas.

Iten: un ropero de madera con tres gavetas. 
Iten: una basa de San Antonio, ya indicada.

Iten: una mesa de tea.

Iten: tres bancos y cuatro tablas para el sotabanco.

Iten: una silla portrona, y otra vieja en la Sacristia.

Iten: dos escaleras.

Iten: tres escaños de pino, digo seis quemados.

Iten: cuatro bland[enes] de madera.

Iten: cuatro candeleros grandes y dos pequillos.

Iten: dos ciriales de palo.

Iten: tres carteras.

Iten: un pulpito con su crucifijo.

Iten: seis candeleros de metal blanco grandes.

Iten: cuatro ídem pequeños de metal dorado.

Iten: dos candelabros.

Iten: un incensario de platica.

Iten: dos faroles grandes y dos pequeños.

Iten: cuatro floreros.

Iten: cuatro redomas.

Iten: seis sacras.

Iten: una arańa en el centro de la Iglesia.

Iten: dos arańas más de platica que se encontraban en la Sacristia y que se habían llevado de la Parroquia para la festividad del Santo en su dia en el mes de Junio.

Iten: un órgano.

\section{HORNAMENTO}

Primeramente: cuatro casullas violada, encarnadas, verde, mas otra encarnada nueva.

Iten: una blanca nueva.

Iten: un sobre caliz de tafetán blanco.

Iten: otro de tafetán encarnado.

Iten: otro de terciopelo de seda verde.

Iten: bolsas de corporal de tafetán blanco y $[\mathrm{r}] \mathrm{ucar}(. .$.$) .$

Iten: mantel, alba amito, paño de lavabo, y de caliz.

Iten: una manga de cruz tafetán blanco.

Iten: una capa de ídem para las procesiones.

Iten: cíngulos blancos y encarnado.

Iten: una capa de lampaso violado con [samaron] de oro San Antonio.

Iten: otra de seda morada también del mismo Santo.

Iten: otra ídem de seda violada de San Bernardo.

Iten: una camisita nueva del niño.

Iten: dos vestidos también de nińo nuevos.

Iten: una capa de terciopelo encarnada del niño.

Iten: otra amarilla nueva.

Iten: tras capas más, dos de San Antonio y una de San Roque. 
Iten: cuatro [cogullas].

Iten: dos capas de niño ya dichas.

Iten: dos de San Roque, azul y otra [mala].

Iten: un frontal verde de la evidencia.

Iten: dos alfombras una vieja y otra nueva.

Iten: un sitial.

Iten: varios ramos de flores en número de veinte y ocho.

Iten: cuatro misales, dos nuevos y dos viejos.

Iten: una vidriera en el nicho del Santo.

Iten: dos barandagas.

Iten: un banco pequeño.

Iten: un trono y tablas.

Iten: varios esbotos de plata y oro que colgaban de la peana del [Santo].

Iten: una hoja de plata que colgaba de su mano, símbolo [de la] hoja de tabaco, la cual se encontró entre los escombros del fuego y se guarda calcinada en el archivo parroquial.

Iten: una pelcha.

Iten: catorce libras cera labrada.

Todo lo cual está conforme con el inventario que [firma] el Párroco D. Domingo Hernández Francisco al hacer entrega de dicha Ermita al Sor. Cura Regente D. Antonio Sanchez Rodriguez, el cual recibio en veinte y cinco de Abril año mil novecientos uno.

En el Archivo Parroquial se guardan algunos residuos inútiles de varios objetos encontrados entre los escombros. Ademas se guarda en dicho archivo la campana de la Ermita en buen estado, pues se salvó de las llamas toda vez que no hay desperfectos en ella y su sonido es propio y natural.

Y para que conste extiendo la presente acta que firman conmigo

El Párroco Antonio Fernandez Rodr.

El Notario Eclesiástico Jose Ma Rodrigues Per.

Testigos Jose Rom[bol] ${ }^{13}$.

13 Archivo Parroquial de Nuestra Señora de Candelaria, Tijarafe (APNSCT, Tijarafe). Documentos varios. Inventario de la Ermita de San Antonio de Padua, Garafía, 1902, s/f. 